\title{
Posterior segment causes of reduced visual acuity after phacoemulsification in eyes with cataract and obscured fundus view
}

This article was published in the following Dove Press journal:

Clinical Ophthalmology

6 November 2012

Number of times this article has been viewed

\author{
Hisham M Jammal ${ }^{1,3}$ \\ Yousef Khader ${ }^{2}$ \\ Riham Shawer ${ }^{3}$ \\ Muawyah Al Bdour ${ }^{4}$ \\ 'Department of Ophthalmology, \\ Jordan University of Science and \\ Technology, Irbid, Jordan; ${ }^{2}$ Department \\ of Community Medicine, Public \\ Health and Family Medicine, Jordan \\ University of Science and Technology, \\ Irbid, Jordan; ${ }^{3}$ Department of \\ Ophthalmology, King Abdullah \\ University Hospital, Irbid, Jordan; \\ ${ }^{4}$ Department of Ophthalmology, \\ The University of Jordan, Amman, \\ Jordan
}

Purpose: To determine posterior segment causes of reduced visual acuity after phacoemulsification in eyes with cataract and obscured fundus view.

Patients and methods: Retrospective review of medical records of patients with cataract, obscured fundus view, and normal B-scan ultrasonography, undergoing phacoemulsification from May 2005 to March 2012 was conducted. Eyes with fundus pathology, previous trauma, surgery, glaucoma, amblyopia, or uveitic cataract were excluded. Ocular comorbid conditions, preoperative visual acuity (VA), intraoperative and early postoperative complications, and final best corrected visual acuity (BCVA) at 1 month were abstracted from the records.

Results: All 201 eyes of 179 patients studied had a preoperative VA of $\leq 6 / 60$. Preoperative ocular comorbidity was present in 31 eyes (15.5\%). Intraoperative complications occurred in 20 eyes (10\%). Postoperative complications developed in 34 eyes (17.0\%). One month postoperatively, 175 eyes $(87.1 \%)$ achieved a BCVA of $\geq 6 / 12$; whereas 26 eyes $(12.9 \%)$ achieved a BCVA of $\leq 6 / 18$. The most common posterior segment causes of reduced VA in the 26 eyes were age-related macular disease in ten eyes (38.5\%) and diabetic maculopathy in six eyes $(23.1 \%)$. Similar fundus pathology was seen preoperatively in the fellow fundus in 10 of the 26 eyes (38.5\%).

Conclusion: One month after phacoemulsification in eyes with cataract and obscured fundus view, age-related macular disease and diabetic maculopathy were the most common posterior segment causes of reduced final BCVA. To avoid postsurgical dissatisfaction, patients with obscured fundus view in their preoperative eye should be counseled, especially if posterior segment pathology exists in their fellow eye.

Keywords: B-scan ultrasonography, fundus view, macula, outcome, phacoemulsifcation

\section{Introduction}

Cataract extraction with lens implantation is a frequently performed surgical procedure worldwide. Cataract extraction is cost effective and has a high success rate and a low complication rate. ${ }^{1}$ However, up to $29 \%$ of eyes undergoing cataract surgery may have a copathology that can cause a guarded prognosis. ${ }^{2}$ Many conditions, such as age-related macular degeneration, glaucoma, and diabetic retinopathy, are readily diagnosed before surgery by clinical examination of the anterior segment and the fundus. However, in patients with dense or mature cataract, the fundus view may be obscured or not visible at all. Viewing the fundus is crucial, not only to predict the visual outcome, but also to manage conditions that can be adversely affected by cataract surgery, such as diabetic retinopathy or peripheral retinal tears. B-scan ultrasonography is used to rule out
Correspondence: Hisham Jammal PO Box 1099, Irbid 21 I I0, Jordan Tel +96279531281 I

Fax +96227200624

Email hishamjammal@hotmail.com 
certain gross retinal pathologies such as retinal detachment, posterior staphyloma, and vitreous hemorrhage, ${ }^{3}$ but it will not adequately assess fine pathologies. Examination of the fundus in the fellow eye may provide a clue in some cases, but may not be helpful in others, as some lesions are usually unilateral or asymmetrical.

When patients give their consent for cataract surgery, they are informed of the high success rate of the procedure, from which nearly $95 \%$ of eyes with no ocular comorbidity can achieve a postoperative best corrected visual acuity (BCVA) of $\geq 6 / 12$. $^{2,4}$ This rate of success, however, cannot be applied to eyes whose fundus is obscured or not visible, as an undiagnosed pathology in the posterior segment can cause an unexpected postoperative result. In this study, we attempted to assess previously undiagnosed posterior segment causes of reduced visual acuity (VA) after cataract extraction in eyes with an obscured or non-visible fundus.

\section{Materials and methods}

This retrospective descriptive study was carried out at King Abdullah University Hospital in Jordan, a teaching hospital affiliated with Jordan University of Science and Technology. Ethical approval was obtained from the Institutional Review Board at the Jordan University of Science and Technology. The clinical notes of 1200 patients who underwent phacoemulsification with intraocular lens implantation between May 2005 and March 2012 were reviewed. Eyes included in the study had dense or mature cataract in which the fundus was not visible or the fundus was obscured, preventing adequate assessment of the posterior pole. For all study eyes, no gross pathology was indicated on B-scan ultrasonography (EchoScan US 3300; Nidek Corp, Gamagori, Japan).

The excluded eyes had a previous, known history of retinal pathology, ocular surgery, glaucoma, amblyopia, trauma, uveitis, laser treatment, or presence of a relative afferent pupillary defect (RAPD). Also excluded were eyes of patients where VA could not be assessed due to cognitive disorders. Applying the inclusion/exclusion criteria resulted in 231 eyes eligible for the study. Thirty eyes were then excluded due to inadequate follow-up and/or inadequate data in the records, leaving a total of 201 eyes included in the study.

All surgeries were performed by one surgeon (HJ) using the Millennium phaco machine (Bausch and Lomb Surgical, Rochester, NY), and the eye with the worse vision was operated on first. Phacoemulsification was performed through a superior clear cornea incision. Trypan-blue staining of the anterior capsule was performed when needed. In all eyes, a single piece acrylic posterior-chamber intraocular lens $\left(\right.$ Akreos $^{\circledR}$ Adapt AO or Akreos ${ }^{\circledR}$ Adapt; Bausch \& Lomb, Rochester, NY) was implanted in the capsular bag. For the intraocular lens-power calculation, Hoffer Q formula was used for axial lengths less than $22 \mathrm{~mm}$, and SRK/T formula was used for all other eyes, including highly myopic eyes. Postoperatively, all patients were routinely prescribed antibiotic-steroid combination eyedrops: 1 drop every 2 hours for 1 week, and thereafter, 1 drop every 6 hours for 3 weeks. Patients were routinely examined 1 day, 1 week, and 1 month after surgery; their final BCVA was recorded at 1 month.

Data were collected on demographic and ocular characteristics, including ocular comorbidity, intraoperative and postoperative complications, preoperative and postoperative BCVA using a standard Snellen chart, and fundus findings in the fellow eye.

High myopia was present when the axial length of the eye was $\geq 26.5 \mathrm{~mm}$. Clinically significant macular edema (CSME) was recorded as defined by the Early Treatment Diabetic Retinopathy Study report no 19.5 Age-related maculopathy (ARM) and age-related macular degeneration (AMD) were recorded as defined by the International ARM Epidemiological Study Group. ${ }^{6}$

Data were described using the Statistical Package for Social Sciences (version 19; IBM Corporation, Armonk, NY). Frequencies, percentages, and cross-tabulations were used to describe categorical variables. Means and standard deviations (SDs) were used to describe continuous variables.

\section{Results}

A total of 201 eyes (99 right and 102 left) of 179 patients (97 females and 82 males) were included in the analysis. The mean (SD) age of the 179 patients was 63.9 (13.3) years (range: 26 to 92 years). Twenty-nine patients (14.4\%) had type- 2 diabetes mellitus. The median follow-up of the operated eyes was 30 days (range: 28 to 30 days).

Preoperatively, the BCVA was $6 / 60$ in $11.9 \%$, counting fingers (CF) in $58.7 \%$, hand motion in $26.9 \%$, and perception of light in $2.5 \%$ of the eyes. The majority of eyes (84.5\%) did not exhibit any preoperative comorbidity. The distribution of preoperative ocular comorbidities is shown in Table 1.

Intraoperative complications are shown in Table 2. The majority of eyes $(90.0 \%)$ did not develop any significant complication. Posterior capsule rupture with vitreous loss was the most common complication and occurred in seven eyes $(3.5 \%)$.

Postoperatively, complications developed in 34 eyes (17.0\%). Complications were primarily related to corneal 
Table I Preoperative ocular comorbidity

\begin{tabular}{lll}
\hline Condition & $\begin{array}{l}\text { Number } \\
\text { of eyes }\end{array}$ & Percentage \\
\hline None & 170 & 84.5 \\
Phacodonesis/PXF & 17 & 8.5 \\
High myopia & 7 & 3.5 \\
Corneal pathology & 5 & 2.5 \\
CNS disease (empty sella syndrome) & 1 & 0.5 \\
Usher syndrome & $\mathrm{I}$ & 0.5 \\
Total & 201 & 100.0 \\
\hline
\end{tabular}

Abbreviations: CNS, central nervous system; PXF, pseudoexfoliation.

edema/striae in 17 eyes and posterior capsule opacification/ plaque in nine eyes (Table 3 ). None of the eyes developed endophthalmitis.

BCVA at final follow-up is shown in Table 4. A total of $175(87.1 \%)$ eyes achieved a BCVA of $\geq 6 / 12$; whereas $26(12.9 \%)$ eyes achieved a BCVA of $\leq 6 / 18$. Overall, VA improved in 196 eyes $(97.5 \%)$, but remained the same (CF) in five eyes $(2.5 \%)$. This was due to AMD in three eyes, old posterior uveitis in one eye, and a pale optic disc in association with a central nervous system disease (empty sella syndrome) in one eye. None of the eyes worsened after surgery. The mean postoperative spherical equivalent was $0.69 \mathrm{D}(\mathrm{SD}=0.97)$. Figure 1 shows the postoperative BCVA in eyes of diabetic patients and nondiabetic patients.

Table 5 shows the posterior segment causes of reduced VA in 26 eyes (16 eyes of nondiabetic patients and ten eyes of diabetic patients), which achieved a BCVA of less than $6 / 12$ after surgery as well as fundus findings in the fellow eye. The most common pathologies in the operated eyes were agerelated macular disease (ARM in six eyes, AMD in four eyes; $38.5 \%$ ) and diabetic maculopathy in six eyes (23.1\%). Of those 26 eyes, a similar pathology was seen preoperatively in the fellow eye in ten eyes, unrelated pathology or a normal fundus in nine eyes, and fundus view was absent in seven eyes. All the fundus pathologies in the operated and fellow eyes were present and documented in the early postoperative period.

Table 2 Intraoperative complications

\begin{tabular}{lll}
\hline $\begin{array}{l}\text { Intraoperative } \\
\text { complication }\end{array}$ & $\begin{array}{l}\text { Number } \\
\text { of eyes }\end{array}$ & Percentage \\
\hline None & 181 & 90.0 \\
PC rupture with vitreous loss & 7 & 3.5 \\
PC rupture no vitreous loss & 4 & 2.0 \\
Zonule dialysis no vitreous loss & 4 & 2.0 \\
Zonule dialysis with vitreous loss & 2 & 1.0 \\
Iris damage from the phaco tip & 2 & 1.0 \\
Cortical matter remnants & $\mathrm{I}$ & 0.5 \\
Total & $20 \mathrm{I}$ & 100.0 \\
\hline
\end{tabular}

Abbreviation: PC, posterior capsule.
Table 3 Postoperative complications

\begin{tabular}{lll}
\hline $\begin{array}{l}\text { Postoperative } \\
\text { complication }\end{array}$ & $\begin{array}{l}\text { Number } \\
\text { of eyes }\end{array}$ & Percentage \\
\hline None & 167 & 83.0 \\
Corneal edema/striae & 17 & 8.5 \\
PCO/YAG not indicated & 8 & 4.0 \\
High IOP & 5 & 2.5 \\
Cystoid macular edema & 2 & 1.0 \\
PCO/YAG indicated & 1 & 0.5 \\
Decentered IOL & 1 & 0.5 \\
Total & 201 & 100.0 \\
\hline
\end{tabular}

Abbreviations: IOP, intraocular pressure; IOL, intraocular lens; PCO, posterior capsule opacification; YAG, yttrium aluminum garnet.

Of 29 eyes in patients with diabetes, five eyes were found to have CSME and one eye had ischemic maculopathy in the early postoperative period and at 1 month postoperative follow-up. Of the five eyes with CSME, three fellow eyes also showed CSME.

\section{Discussion}

Because advanced surgical techniques are resulting in excellent outcomes and because of media and marketing factors, ${ }^{7}$ in industrialized nations, more patients with relatively good VA present for cataract surgery at an earlier stage. However, in developing countries, many patients still present late, with markedly reduced vision due to many factors, which include economic status, accessibility to health care, the impact of decreased vision on daily living, fear of a poor outcome, lack of family support, and wanting to wait for free surgical services. ${ }^{8}$ Also, many patients also still adopt the concept that a cataract should be "ripe" before seeking surgery. These factors are responsible for the high rate of mature and dense cataracts in our study population (nearly $20 \%$ ). Many of these patients will have their eyes examined for the first time upon presenting with advanced cataracts.

Table 4 Final best corrected visual acuity (BCVA) recorded at one month after surgery

\begin{tabular}{llll}
\hline BCVA & $\begin{array}{l}\text { Number } \\
\text { of eyes }\end{array}$ & Percentage & $\begin{array}{l}\text { Cumulative } \\
\text { percentage }\end{array}$ \\
\hline $6 / 6$ & 122 & 60.7 & 60.7 \\
$6 / 9$ & 36 & 17.9 & 78.6 \\
$6 / 12$ & 17 & 8.5 & 87.1 \\
$6 / 18$ & 10 & 5.0 & 92.0 \\
$6 / 24$ & 3 & 1.5 & 93.5 \\
$6 / 36$ & 3 & 1.5 & 95.0 \\
$6 / 60$ & 4 & 2.0 & 97.0 \\
CF & 6 & 3.0 & 100.0 \\
Total & 201 & 100.0 & \\
\hline Abbravian
\end{tabular}

Abbreviation: $\mathrm{CF}$, counting fingers. 


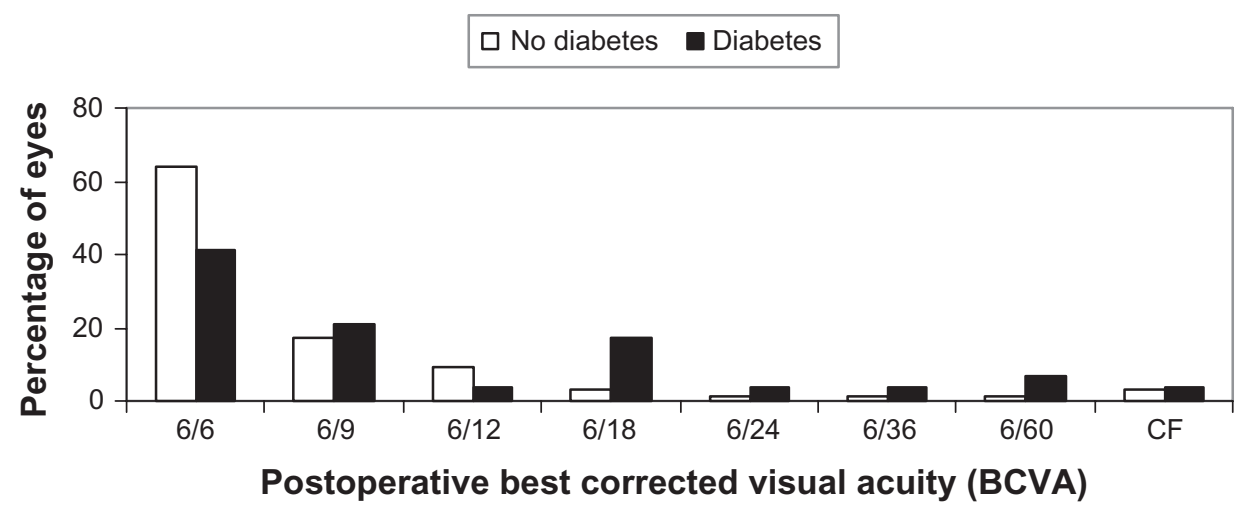

Figure I The postoperative best corrected visual acuity (BCVA) in eyes of diabetic patients and nondiabetic patients.

Therefore, we attempted to assess the posterior segment causes of reduced visual acuity after surgery in order to provide better preoperative patient counseling and avoid patient disappointment if vision failed to improve to expected levels. To the best of our knowledge, we are not aware of any study describing the nature and distribution of such conditions in eyes with an obscured or non-visible fundus.

In this retrospective review, posterior capsule rupture with or without vitreous loss, and zonular dialysis with vitreous loss, occurred in $6.5 \%$ of eyes. This is comparable to the results reported by Muhtaseb et $\mathrm{al}^{9}$ in patients in a risk group similar to our patients with dense, total, white, or brunescent cataracts.

We also found that the frequency of eyes achieving a BCVA of $\geq 6 / 12$ was $87.1 \%$. In the large Cataract National Dataset electronic multicenter audit, Jaycock et $\mathrm{al}^{2}$ reported that the frequency of eyes achieving a best measured VA of $\geq 6 / 12$ was $79.3 \%$ in eyes with brunescent/white cataract and $76.5 \%$ in eyes with no fundal view/vitreous opacities. However, those eyes may have had more than one ocular copathology, many of which, such as glaucoma or uveitis, were excluded from our study. Also, Jaycock et $\mathrm{al}^{2}$ did not specify the causes of reduced postoperative VA, and might have included causes not related to posterior segment pathology. In our study, we included a number of ocular comorbid conditions, such as pseudoexfoliative syndrome, corneal pathology, and high myopia. Our inclusion of these ocular comorbid conditions could affect the comparison with Jaycock et als'2 study outcome, where those patients had no ocular comorbidities and where $94.7 \%$ of eyes improved to $\geq 6 / 12$.

After analyzing the results, we determined that the corneal pathology was not sufficiently severe to affect the final visual outcome, since all five eyes with corneal pathology achieved a final BCVA of $\geq 6 / 12$. Furthermore, pseudoexfoliative syndrome without associated glaucoma has more impact on the rate of intraoperative complications. In our study, we also included highly myopic eyes, as the fundus findings were not known preoperatively, and because myopic maculopathy rather than high myopia is the actual comorbid condition that would be a reason for a guarded visual prognosis.

Table 5 Posterior segment causes of reduced postoperative best corrected visual acuity (BCVA) $(<6 / 12)$ at one month after surgery

\begin{tabular}{|c|c|c|c|c|c|c|c|}
\hline \multirow[t]{2}{*}{ Fundus findings in the operated eye } & \multicolumn{3}{|c|}{ Number of eyes } & \multirow[t]{2}{*}{ Percentage } & \multicolumn{3}{|c|}{$\begin{array}{l}\text { Similar fundus findings } \\
\text { in fellow eye }\end{array}$} \\
\hline & No diabetes & Diabetes & All & & Yes & No & No view \\
\hline ARM: RPE atrophy/drusen & 4 & 2 & 6 & 23.1 & 3 & 2 & I \\
\hline CSME/ischemic maculopathy & 0 & 6 & 6 & 23.1 & 3 & 2 & 1 \\
\hline Dry AMD/wet AMD & 3 & 1 & 4 & 15.4 & 2 & 0 & 2 \\
\hline Optic atrophy & 2 & I & 3 & 11.5 & 0 & 2 & 1 \\
\hline BRVO, macular edema & 2 & 0 & 2 & 7.7 & 0 & 2 & 0 \\
\hline Myopic maculopathy & 2 & 0 & 2 & 7.7 & 2 & 0 & 0 \\
\hline Diffuse chorioretinal degeneration & 1 & 0 & I & 3.8 & 0 & 0 & I \\
\hline Nonspecific macular scar & 1 & 0 & I & 3.8 & 0 & 0 & I \\
\hline Old posterior uveitis and macular scar & 1 & 0 & I & 3.8 & 0 & $\mathrm{I}$ & 0 \\
\hline Total & 16 & 10 & 26 & 100.0 & 10 & 9 & 7 \\
\hline
\end{tabular}

Abbreviations: AMD, age-related macular degeneration; ARM, age-related maculopathy; BRVO, branch retinal vein occlusion; CSME, clinically significant macular edema; RPE, retinal pigment epithelium. 
In our retrospective study, the main causes of failure to achieve a BCVA of $\geq 6 / 12$ were age-related macular disease (ARM and AMD) and diabetic maculopathy. Two previous studies $^{10,11}$ also showed those entities to be the main causes of patient dissatisfaction after phacoemulsification, apart from being common premorbid conditions in patients presenting for cataract surgery. However, in both studies, the presence of these pathologies was preoperatively detected. We also found that the same pathology (ARM, AMD, diabetic maculopathy) was present preoperatively in the fellow eye in $50 \%$ of those patients. To the surgeon, the preoperative presence of these conditions in the fellow eye should raise suspicion of a possible macular abnormality in the surgery eye, and the surgeon should take this into consideration when counseling the patient on the expected visual outcome.

The effect of cataract surgery on the progression of preexisting diabetic macular edema is still under debate, ${ }^{12}$ as is evidence for progression of AMD after cataract extraction; but recent studies reported increased risk of dry $\mathrm{AMD}^{13}$ and late AMD. ${ }^{14}$ Therefore, when the surgeon is confronted with a scenario where the fundus of the surgery eye is not visible, and the fellow eye shows CSME or AMD, preoperative counseling should include discussion of the possible fundus pathologies that could affect the VA outcome or that could be adversely affected by cataract surgery.

At the completion of cataract surgery, indirect ophthalmoscopic examination of the posterior pole can help diagnose some of these conditions, and recently, intraoperative optical coherence tomography (OCT) has been used in retinal imaging. ${ }^{15}$ Though in its early stages, intraoperative OCT can help with the diagnosis of macular pathologies and aid in deciding on appropriate interventions, such as using intravitreal agents. Intraoperative use of such agents has the advantage of earlier intervention, less patient discomfort or apprehension while injecting, and theoretically less risk of infection, as the patient's eye is already scrubbed in theater. Closer postoperative monitoring may also improve the visual outcome in such patients.

In the three cases found to have optic atrophy, one patient was known to have empty sella syndrome, with bilateral mature cataracts and no fundus view in the fellow eye. An RAPD was not present preoperatively, possibly due to optic atrophy in the other eye, which had no fundus view either. In the other two eyes with unilateral optic atrophy, RAPD was not detected preoperatively, and this might be explained by the observation that an asymmetric cataract can produce RAPD in the contralateral eye with a less severe cataract. ${ }^{16,17}$ Applying this concept, if an eye with a preexisting optic nerve dysfunction and an RAPD develops an advanced cataract, this defect would be masked or reversed later because of the development of contralateral RAPD.

The other causes of reduced BCVA were variable and could not have been predicted by examining the fellow fundus, mainly due to the unilateral nature of the pathologies involved. However, two eyes with myopic maculopathy, a commonly bilateral disease, had similar lesions in the fellow fundus.

Apart from history and ocular examination, several potential vision testing techniques, such as the potential acuity meter and the laser interferometer, have been used to test the neuroretinal integrity and predict VA after cataract surgery, but were of very limited value or usefulness in the presence of dense cataracts. Recent reports, however, showed that measurement of the critical flicker frequency (CFF) threshold as a potential vision testing technique had greater predictive accuracy, ${ }^{18,19}$ particularly with dense cataracts, and was less affected by dense opacities, especially with the use of a brighter stimulus. ${ }^{20,21} \mathrm{CFF}$ can be used to predict postoperative visual outcomes in patients where the fundus view is obscured. The equipment is affordable, and measurements are relatively easy to perform. ${ }^{20}$

Although 10 out of 26 eyes had a similar pathology in the fellow eye, preoperatively, the small number of cases in this group did not allow predictions of statistical significance to be made regarding visual outcomes after surgery. Likewise, neither the severity of preoperative visual impairment nor postoperative VA was helpful in such a small group.

In summary, age-related macular disease (ARM and AMD) and diabetic maculopathy were the main reasons for reduced visual outcomes after cataract surgery in eyes where the view of the fundus was obscured or not visible. The presence of similar findings in the fellow eye increases the possibility of a guarded prognosis. In such cases, more detailed patient counseling, use of a proper potential vision testing technique such as CFF, and consideration of further intraoperative interventions in certain selected cases (eg, intravitreal injections) can help avoid patients' disappointment after surgery and maximize visual outcomes.

\section{Disclosure}

The authors report no conflicts of interest in this work.

\section{References}

1. Lansingh VC, Carter MJ, Martens M. Global cost-effectiveness of cataract surgery. Ophthalmology. 2007;114(9):1670-1678.

2. Jaycock P, Johnston RL, Taylor H, et al. The Cataract National Dataset electronic multi-centre audit of 55,567 operations: updating benchmark standards of care in the United Kingdom and internationally. Eye (Lond). 2009;23(1):38-49. 
3. Anteby, II, Blumenthal EZ, Zamir E, Waindim P. The role of preoperative ultrasonography for patients with dense cataract: a retrospective study of 509 cases. Ophthalmic Surg Lasers. 1998;29(2):114-118.

4. Lundstrom M, Stenevi U, Thorburn W. The Swedish National Cataract Register: a 9-year review. Acta Ophthalmol Scand. 2002;80(3): 248-257.

5. Group ETDRSR. Focal photocoagulation treatment of diabetic macular edema. Relationship of treatment effect to fluorescein angiographic and other retinal characteristics at baseline: ETDRS report no 19. Early Treatment Diabetic Retinopathy Study Research Group. Arch Ophthalmol. 1995;113(9):1144-1155.

6. Bird AC, Bressler NM, Bressler SB, et al. An international classification and grading system for age-related maculopathy and age-related macular degeneration. The International ARM Epidemiological Study Group. Surv Ophthalmol. 1995;39(5):367-374.

7. Dua HS, Said DG, Otri AM. Are we doing too many cataract operations? Cataract surgery: a global perspective. Br J Ophthalmol. 2009;93(1): $1-2$.

8. Chang MA, Congdon NG, Baker SK, Bloem MW, Savage H, Sommer A. The surgical management of cataract: barriers, best practices and outcomes. Int Ophthalmol. 2008;28(4):247-260.

9. Muhtaseb M, Kalhoro A, Ionides A. A system for preoperative stratification of cataract patients according to risk of intraoperative complications: a prospective analysis of 1441 cases. Br J Ophthalmol. 2004;88(10):1242-1246.

10. Chatziralli IP, Kanonidou E, Papazisis L. Frequency of fundus pathology related to patients' dissatisfaction after phacoemulsification cataract surgery. Bull Soc Belge Ophtalmol. 2011;317:21-24.

11. Monestam E, Wachtmeister L. Dissatisfaction with cataract surgery in relation to visual results in a population-based study in Sweden. J Cataract Refract Surg. 1999;25(8):1127-1134.
12. Shah AS, Chen SH. Cataract surgery and diabetes. Curr Opin Ophthalmol. 2010;21(1):4-9.

13. Ho L, Boekhoorn SS, Liana, et al. Cataract surgery and the risk of aging macula disorder: the Rotterdam study. Invest Ophthalmol Vis Sci. 2008;49(11):4795-4800.

14. Klein BE, Howard KP, Lee KE, Iyengar SK, Sivakumaran TA, Klein R. The relationship of cataract and cataract extraction to age-related macular degeneration: the Beaver Dam Eye study. Ophthalmology. 2012;119(8):1628-1633.

15. Hahn P, Migacz J, O’Connell R, Maldonado RS, Izatt JA, Toth CA. The use of optical coherence tomography in intraoperative ophthalmic imaging. Ophthalmic Surg Lasers Imaging. 2011;42 Suppl: S85-S94.

16. Hwang JM, Kim C, Kim JY. Relative afferent pupillary defect in patients with asymmetric cataracts. J Cataract Refract Surg. 2004;30(1): 132-136.

17. Lam BL, Thompson HS. A unilateral cataract produces a relative afferent pupillary defect in the contralateral eye. Ophthalmology. 1990;97(3):334-338.

18. Vianya-Estopa M, Douthwaite WA, Noble BA, Elliott DB. Capabilities of potential vision test measurements: clinical evaluation in the presence of cataract or macular disease. J Cataract Refract Surg. 2006;32(7): $1151-1160$

19. Douthwaite WA, Vianya-Estopa M, Elliott DB. Predictions of postoperative visual outcome in subjects with cataract: a preoperative and postoperative study. Br J Ophthalmol. 2007;91(5):638-643.

20. del Romo GB, Douthwaite WA, Elliott DB. Critical flicker frequency as a potential vision technique in the presence of cataracts. Invest Ophthalmol Vis Sci. 2005;46(3):1107-1112.

21. Shankar H, Pesudovs K. Critical flicker fusion test of potential vision. $J$ Cataract Refract Surg. 2007;33(2):232-239.
Clinical Ophthalmology

\section{Publish your work in this journal}

Clinical Ophthalmology is an international, peer-reviewed journal covering all subspecialties within ophthalmology. Key topics include: Optometry; Visual science; Pharmacology and drug therapy in eye diseases; Basic Sciences; Primary and Secondary eye care; Patient Safety and Quality of Care Improvements. This journal is indexed on

\section{Dovepress}

PubMed Central and CAS, and is the official journal of The Society of Clinical Ophthalmology (SCO). The manuscript management system is completely online and includes a very quick and fair peer-review system, which is all easy to use. Visit http://www.dovepress.com/ testimonials.php to read real quotes from published authors. 